\title{
A Sensor System for Online Oil Condition Monitoring of Operating Components
}

\author{
Manfred R. Mauntz, Jürgen Gegner, \\ Ulrich Kuipers and Stefan Klingau \\ Additional information is available at the end of the chapter \\ http://dx.doi.org/10.5772/55737
}

\section{Introduction}

A web-based oil diagnosis system for continuous online lubricant condition monitoring is presented. The new approach utilizes sensor detection of chemical aging of engineering oils and their additives or first traces of wear debris by precision measurement of the electrical properties. The basic concept and physical background are introduced in detail.

The application potential of the sensor system is discussed on the example of the early identification of critical operating conditions for premature white etching cracks failures of rolling bearings in industrial gearboxes. Causative vibration loading is revealed prior to any component damage. Large roller bearings in wind energy gearboxes unusually often fail prematurely, i.e. clearly before the nominal $L_{10}$ life. The failure is characterized by axial raceway cracks, from which branching and spreading crack systems, partly decorated by white etching microstructure, develop into the depth by corrosion fatigue. High localized friction coefficients, resulting from the specific vibration caused mixed friction operating conditions, initiate tensile stress induced cleavage-like brittle spontaneous surface cracking. The basic idea of the novel failure detection condition monitoring system is the early identification of chemical aging of the lubricant and its additives under the influence of vibration loading.

The sensor effectively controls the proper operation conditions of, e.g., bearings and gears in gearboxes. The online diagnostics system measures components of the specific complex impedance of oils. For instance, metal abrasion due to wear debris, broken oil molecules, forming acids or oil soaps, result in an increase of the electrical conductivity, which directly correlates with the degree of contamination of the oil. For additivated lubricants, the stage of degradation of the additives can also be derived from changes in the dielectric constant. The determination of the reduction in the oil quality by contaminations and the quasi continuous evaluation of wear and chemical aging follow the holistic approach of a real-time monitoring 
of an alteration in the condition of the oil-machine system. The measuring signals can be transmitted online to a web-based monitoring system via LAN, WLAN or serial interfaces of the sensor. Control of the relevant damage mechanisms, e.g. tribiological wear or oil aging, during proper operation below certain tolerance limits then allows preventive, conditionoriented maintenance to be carried out, if necessary, long before regular overhauling. Outage durations are reduced and the life of components and machines is increased.

\section{Basic sensor concept and physical principles}

\subsection{Basic sensor concept}

The basic sensor concept of the novel engineering oil monitoring system is based on the measurement of complex oil impedance components $X$, particularly the specific electrical conductivity $\kappa$ and the relative permittivity $\varepsilon_{\mathrm{r}}$. Due to their temperature dependence, the oil temperature $T$ is also recorded [1-3]. Two or more electrodes, between which the oil flows, serve as a basic sensor. Resistance and capacity are measured independently of each other. Zero-mean periodic quantities are used to prevent polarization effects. Figure 1 shows the sensor in its triple plate design.

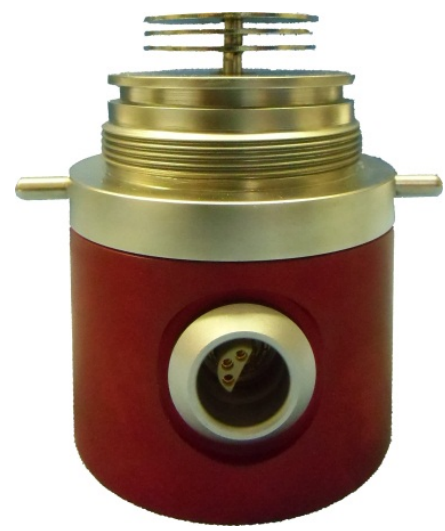

Figure 1. Sensor in triple plate design.

Oils are electrical non-conductors. The electrical residual conductivity of pure oils lies in the range below $1 \mathrm{pS} / \mathrm{m}$. For comparison, the electrical conductivity of the electrical non-conductor distilled water is larger by six orders of magnitude.

Broken oil molecules, acids, abrasive (metallic) wear, ions, oil soaps, etc., cause an increase of the oil conductivity $\kappa$. It rises with increasing ion concentration and mobility. The electrical conductivity of almost all impurities is high compared to the extremely low corresponding property of original pure oils.

The basic sensor represents an electrode arrangement, in which the measured oil is used as electrical conductor and as dielectric material for conductivity and relative permittivity 


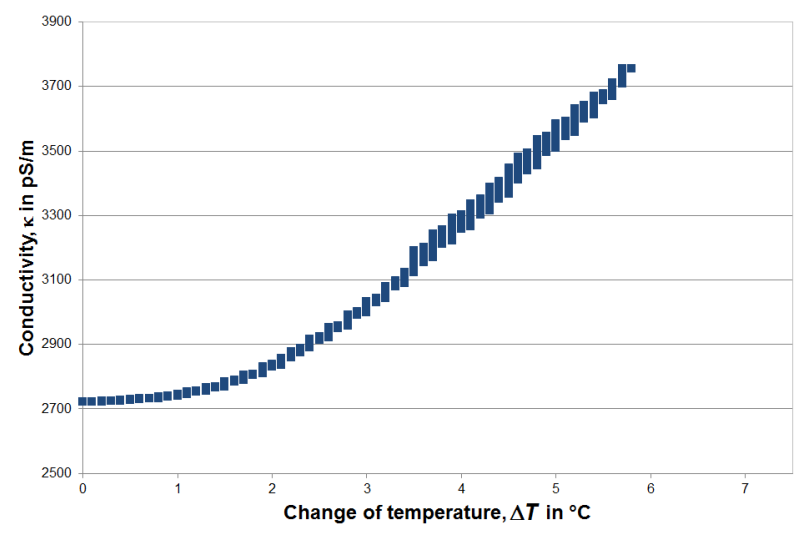

Figure 2. Temperature dependence of the electrical conductivity of sample oil.

measurement, respectively. Oil is an electrical non-conductor. High resistance of the basic sensor and resulting low measurement currents provide best interference sensitivity to interspersed electromagnetic fields. Due to the very small currents, moreover, sufficient interference suppression is achieved. To prevent polarization effects, zero-mean alternating current voltages are measured as test signals. However, no capacitive current components may be measured simultaneously during a conductivity measurement because the capacitive current is much higher than its ohmic components. Thus, rather high requirements are set on analog sensor electronic systems, which are met with the reported measurement procedure.

The conductivities of the insulating construction elements and insulation of electrical feedthrough are about the same size as for the pure oils to be analyzed. The developed basic sensors and precise sensor electronic system ensure that the conductivity of feedthroughs and substrates may not be included into the test results. The active basic sensor unit consists of two or several basic sensor plates which are fixed to metal pins of a glass/metal feedthrough in a constant distant from each other. The plates of the basic sensor are arranged in the middle of the measuring chamber, allowing for an adequate incident flow of the flowing medium. A special alignment of the sensor housing parts is thus not necessary in this design. The extension characteristics of the sensor housing materials and the glass/metal feedthrough pins are exactly adjusted to the material characteristics of the used feedthrough glass. The compression strength is above $10 \mathrm{MPa}$

\subsection{Temperature compensation}

The ion mobility and thus the electrical conductivity $\kappa$ depend upon the internal friction of the oil and therefore also on its temperature. The oil conductivity increases with temperature. Figure 2 shows the dependence of the conductivity $\kappa$ on the temperature change $\Delta T$.

Already for about $3{ }^{\circ} \mathrm{C}$ alteration in temperature, the conductivity changes by about $25 \%$. The electrical conductivity $\kappa$ is a temperature function that depends on oil impurities rather than on the oil itself. The type of pollution and its temperature dependence cannot be assumed to 
be known. To improve the comparability of measurements, a self-learning adaptive temperature compensation algorithm is implemented. An integral alteration of the oil quality can then be assessed by the temperature compensated conductivity value, whereas the type of contamination is not determinable. The relative permittivity is measured with the same basic sensor arrangement as used for the electrical conductivity.

The electrical conductivity and relative permittivity are to be measured with respect to a reference temperature $T_{R}$ as close as possible to the operating temperature of the oil. These parameters can be evaluated by means of temperature-dependent approximating polynomials, as demonstrated below exemplarily for the electrical conductivity:

$$
\kappa_{\mathrm{R}}=\kappa_{\mathrm{R}, 0}+\left(a \Delta T_{\mathrm{C}}+b \Delta T_{\mathrm{C}}^{2}+c \Delta T_{\mathrm{C}}^{3}\right) \times \kappa_{\mathrm{M}}
$$

Here, $\kappa_{R}$ and $\kappa_{R, 0}$ denote the approximate and previously calculated (old) electrical conductivity of the oil at the reference temperature $T_{R}$, respectively. $T_{C}$ stands for the current temperature of the oil and $\kappa_{\mathrm{M}}$ is the electrical conductivity measured without temperature compensation. Moreover, $a, b$, und $c$ are the coefficients of the approximating polynomial to be adaptively determined. The temperature difference is defined as follows:

$$
\Delta T=T_{R}-T_{C}
$$

The oil temperature $T_{\mathrm{C}}$ is measured for this temperature compensation. The use of a polynomial of the third order in Eq. (1) ensures good approximation while keeping the computational effort for the applied microcomputer reasonably low. Figure 3 shows the measured values of the electrical conductivity $\kappa$ after temperature compensation.

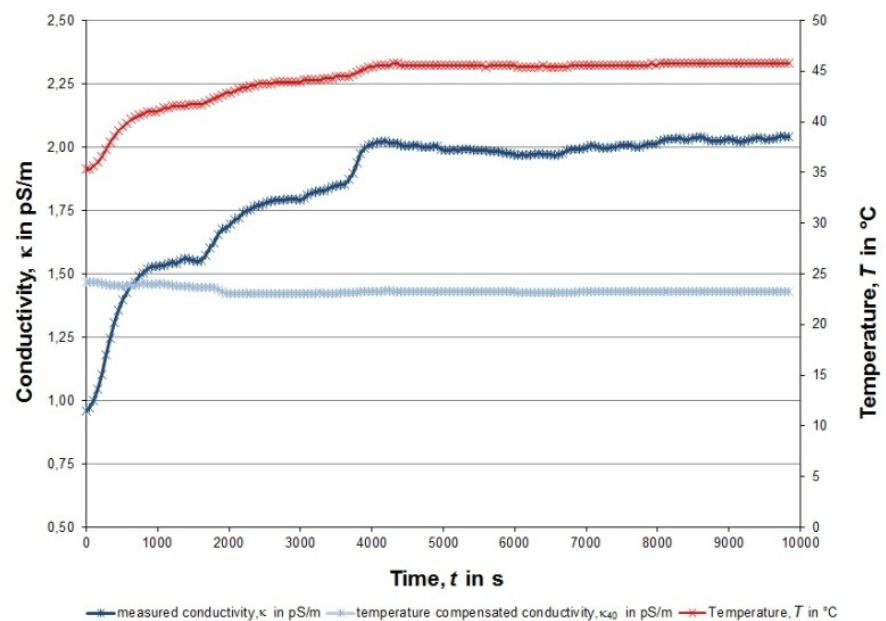

Figure 3. Measured conductivity values after temperature compensation. 


\subsection{Calculation and linear approximation of relative permittivity and conductivity}

In a series of experiments on the non-additivated lubricating oil FVA03, fresh demineralized water was added to a volume of $3.01 \%$. The oil conductivity data measured as a function of the water content are found to follow a linear relationship in good approximation. The theoretical course of the relative permittivity is calculated for dilute solutions according to different mixing rules by truncating a Taylor series expansion of the model equations after the linear term. The model of Lichtenecker is evaluated in Figure 4. Lichtenecker developed the formula of Eq. (3) for calculating the dielectric constant of a homogeneous mixture $\varepsilon_{\mathrm{r}}$ [4]:

$$
\varepsilon_{\mathrm{r}}=\varepsilon_{\mathrm{r}, \mathrm{add}}^{f} \times \varepsilon_{\mathrm{r}, \mathrm{oil}}^{1-f}
$$

The permittivity of the addition and the oil, respectively, is denoted $\varepsilon_{\mathrm{r}, \text { add }}$ and $\varepsilon_{\mathrm{r}, \mathrm{iil}}$. With the volume fraction $f$ of the addition, $1-f$ becomes the volume fraction of the oil.

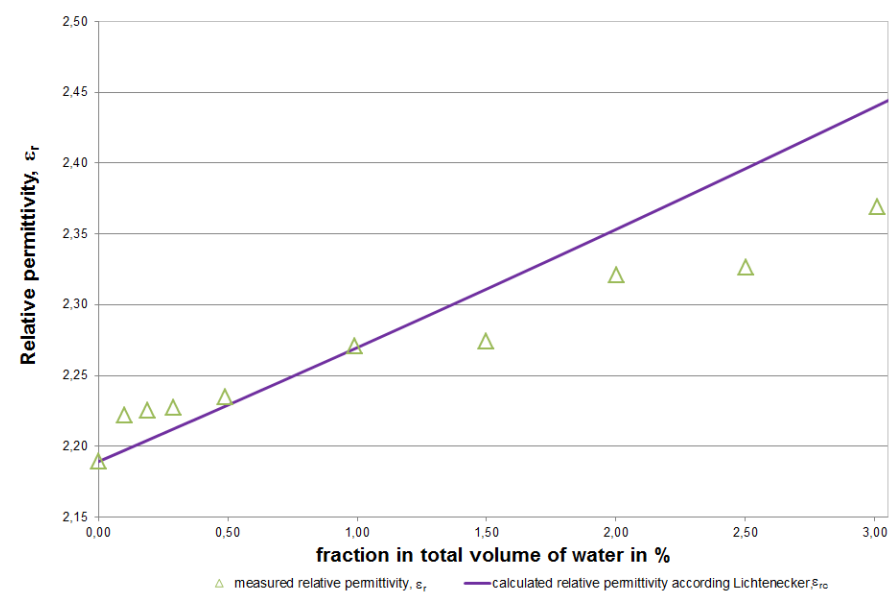

Figure 4. Electrical permittivity $\varepsilon_{\mathrm{r}}$ measured as a function of the water content and model fit according to Eq. (3).

\section{Premature failures of rolling bearings and correlation with oil aging}

Bearings in industrial, e.g. wind turbine, gearboxes unusually often suffer from a significantly shorter life than calculated by white etching cracks $[5,6]$. Figure 5 shows the light-optical micrograph of a typical metallographic microsection [5]. The overrolling direction from left to right indicates surface initiation and top-down propagation of the extended crack system.

These early failures are characterized by mostly axial raceway cracks, revealing vertical semi to fully circular cleavage-like lenticular brittle spontaneous incipient cracks in preparatively opened original fracture faces $[5,6]$. Occasionally, pock-like spallings are associated with the 


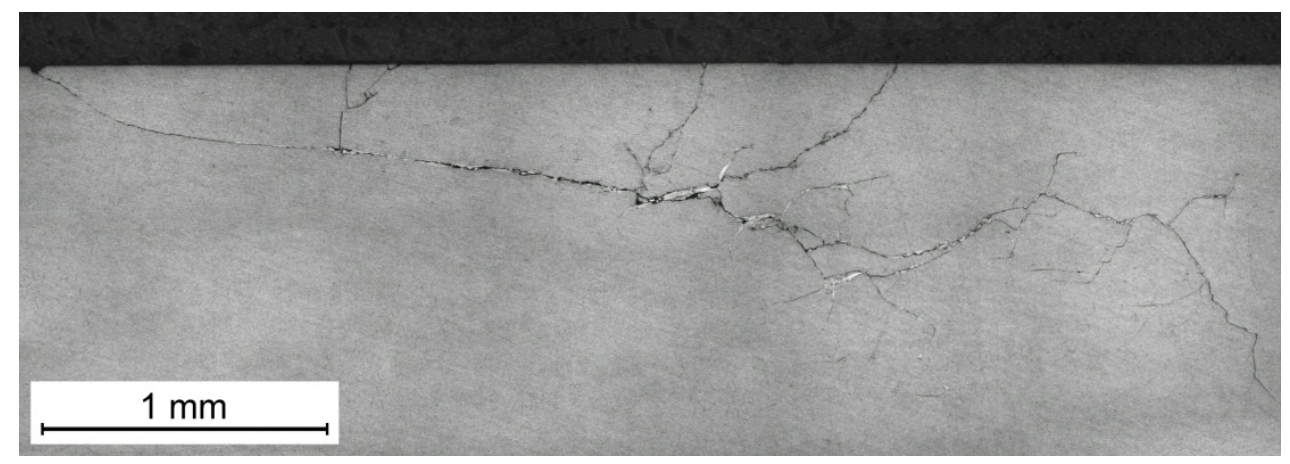

Figure 5. Radial microsection of a branching and spreading white etching crack system.

surface cracks, as shown exemplarily in Figure 6 [6]. The developing deep crack systems are open to the raceway, from which oil penetrates and promotes further corrosion fatigue crack growth as well as local secondary microstructural changes in the form of crack path decorating white etching constituents. It is evident from fractography and X-ray diffraction (XRD) residual stress analyses that the cleavage-like incipient cracks are caused by frictional tangential tensile stresses $[5,6]$, which occur in subregions of the contact area in specific, vibrationally induced mixed friction operating conditions [5-8].

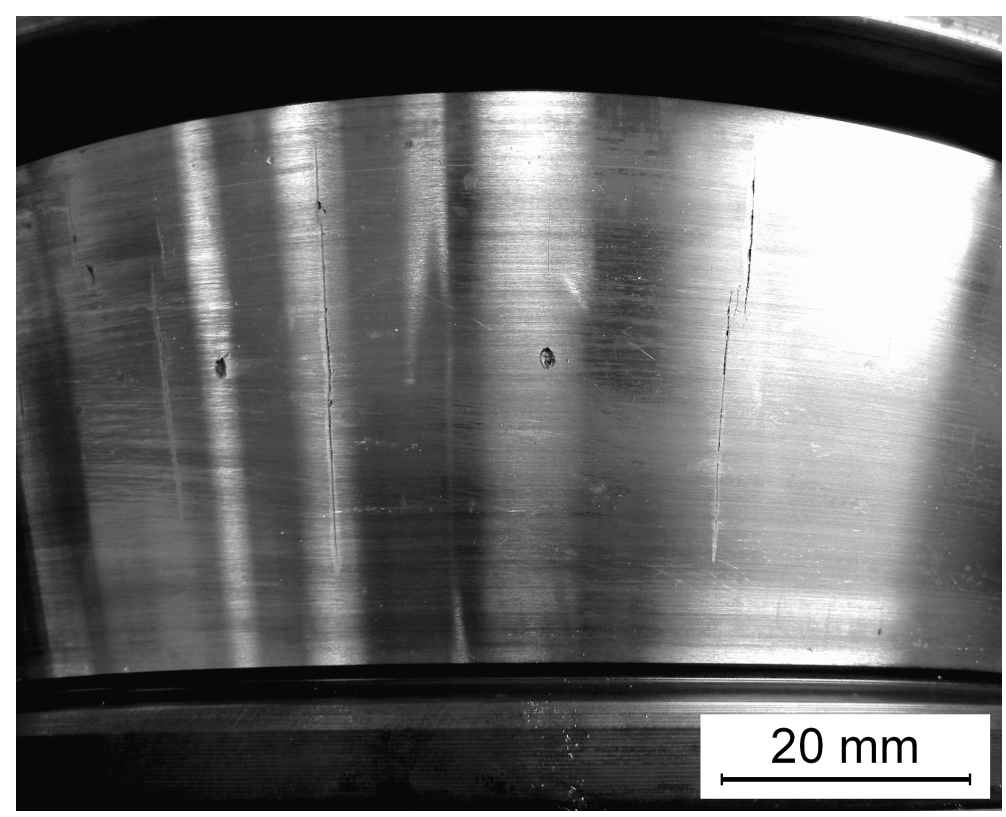

Figure 6. Inner ring raceway with typical axial cracks and few associated pock-like spallings. 
XRD based material response analyses of run rolling bearings, suffering from white etching cracks on still largely undamaged raceways, reveal the causative vibration loading [5]. It is further reported that lubricant aging occurs under the influence of vibrations [7, 8]. An example of an infrared spectrum of used oil from rig test run of a roller bearing is provided in Figure 7 [7]. The verified $\mathrm{O}-\mathrm{H}$ and $\mathrm{C}=\mathrm{O}$ oxidation bands indicate operational acidification of the oil, also reflected in the dissolution of MnS inclusion lines on the raceway (cf. Figure 8), as a result of polycondensation reactions towards resinification and beginning lacquer formation. It is this aging of the lubricating oil and its additives, which can be detected at an early stage by the new sensor so that a gearbox operating at critical conditions is identified.

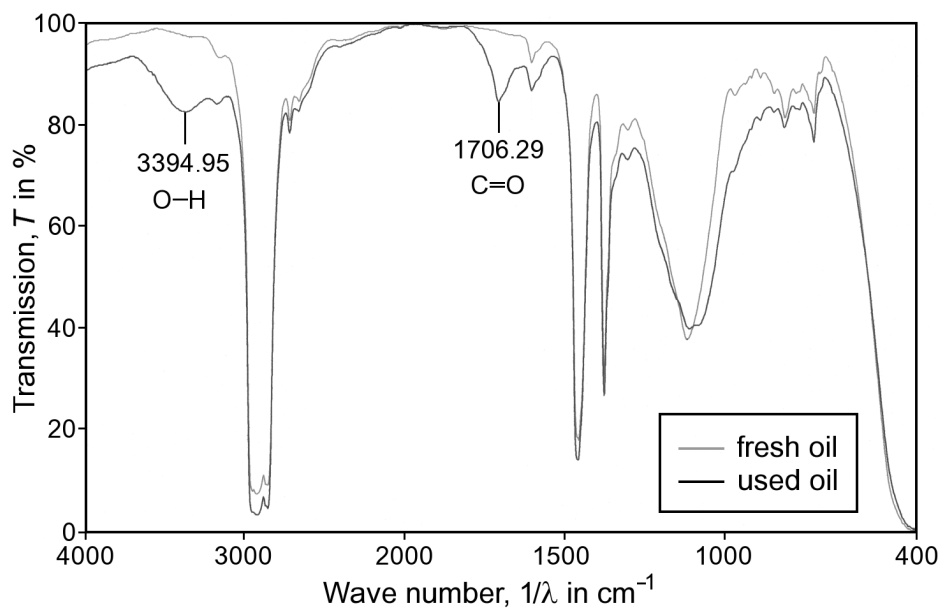

Figure 7. Oxidation peaks in the infrared spectrum of a used non-additivated aliphatic lubricating oil run under vibration loading in a rolling bearing rig test ( $\lambda$ is the wavelength).

The mentioned crack initiation by tribochemical reactions is also found on lateral surfaces of rollers. In Figure 8 [5], a scanning electron microscope (SEM) image, taken in the secondary electron imaging mode, is shown on the left. Residues of manganese and sulphur, detected in the crack-like defect by energy dispersive X-ray spectroscopy (Figure 8 , on the right), indicate the causative tribo chemical dissolution of nonmetallic MnS inclusions [5, 7, 8].

\section{Trial of the oil sensor system on a bearing and gear test rig}

On a bearing and gear test rig, the new sensor based oil quality monitoring system is applied. Various load cycles are run and speeds and torques are measured. The results of the trial are described, evaluated and discussed in the following sections.

\subsection{Loss of power and trial run characteristics}

The speed-related power $P(n)$ of the test rig is given as follows: 

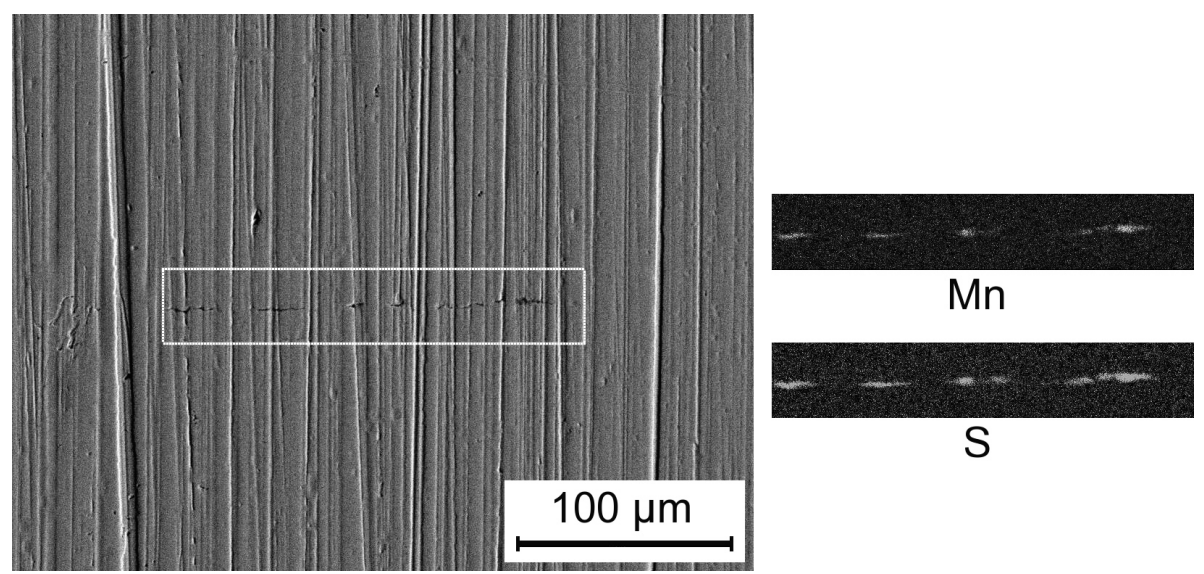

$\mathrm{Mn}$

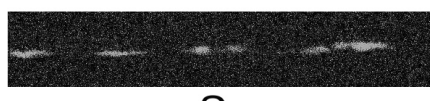

S

Figure 8. SEM image of a crack on a bearing roller with elemental mapping of $\mathrm{Mn}$ and S.

$$
P=M \cdot \omega \text { with } \omega=2 \pi \cdot n
$$

Here, $M$ denotes the torque, $\omega$ and $n$ respectively stand for the angular velocity and rotational speed. The implemented power loss $\Delta P$ is derived from the transmission ratio $N_{\ddot{u}}$ :

$$
\Delta P=\omega_{1} \cdot\left(M_{1}-N_{\ddot{U}} \cdot M_{2}\right)
$$

$M_{1}$ and $M_{2}$ indicate the torque of the drive and the load, respectively. In the first trial on the test rig, the rolling bearing is intentionally damaged. The time-dependent power loss in the gear, as derived from the measuring signal characteristics, is represented in Figure 9.

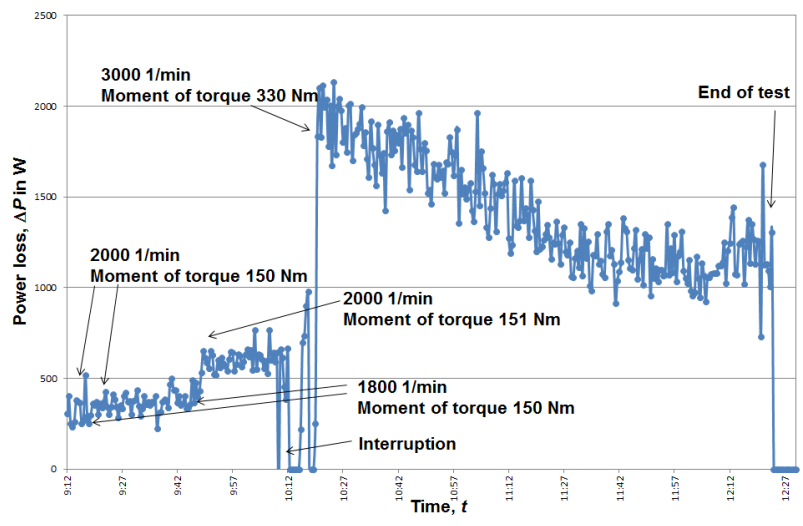

Figure 9. Calculated power loss $\Delta P$. 
After switching to a higher load, the power loss increases abruptly before the bearings run in. Towards the end of the trial, the bearings reveal indication of advanced deterioration. A wide lubrication gap and vibrations when overrolling spalling results in higher oscillation amplitudes, which leads to the automatic shutdown of the test rig eventually. The measuring results obtained with the oil sensor system are presented in the following.

\subsection{Conductivity of the lubricating oil}

Figure 10 shows the test readings of the conductivity measurement of the lubricating oil. The current bearing wear and the deteriorating oil condition in the conducted trial are reflected in the change of the electrical conductivity plotted vs. running time in the diagram.

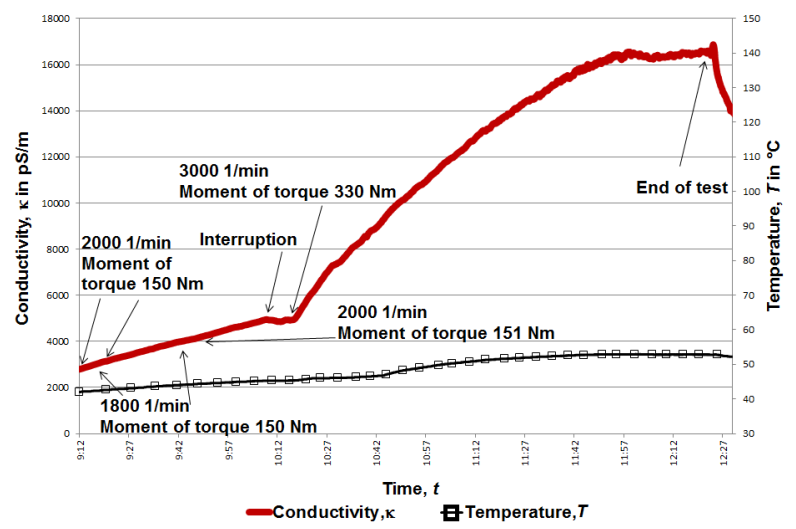

Figure 10. Measurement of the electrical conductivity $\mathrm{k}$ vs. running time $t$.

New oil from the storage container exhibits a conductivity $\kappa$ of $2312 \mathrm{pS} / \mathrm{m}$. After filling into the trial gear and before the start-up of the test rig, a conductivity of $2791 \mathrm{pS} / \mathrm{m}$ is measured. This increase can be attributed to existing residual impurities in the gear. During the trial run, the conductivity $\kappa$ of the gear oil increases to $16868 \mathrm{pS} / \mathrm{m}$. Besides changes in temperature, conductivity increase is caused, e.g., by wear debris and removed material from spalling, impurities, broken oil molecules or forming oil soap. As described above, the temperature dependence of the electrical conductivity of the used gear oil is compensated and the oil conductivity measured in the gear trial is converted into the relevant conductivity value at 40 ${ }^{\circ} \mathrm{C}$. Figure 11 shows the development of the temperature compensated oil conductivity with running time during the gear trial.

In the case of an initially low load, the electrical conductivity increases linearly with running time. It is to be assumed that the low bearing wear in this area also increases proportional to the time.

During the necessary intermediate shutdown (interruption) and run-up of the drive machine to $330 \mathrm{Nm}$, the conductivity is virtually constant. After switching over to the higher load, the 


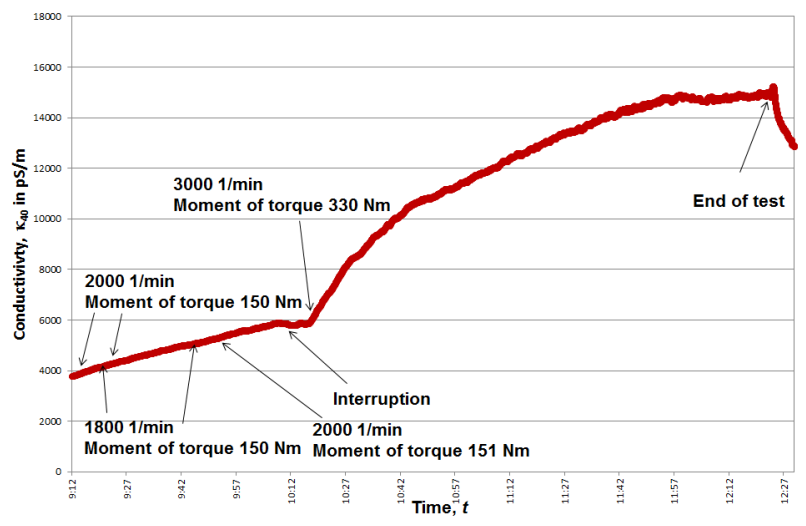

Figure 11. Time curve of the temperature compensated oil conductivity derived from Figure 10.

oil conductivity increases strongly. Here, the bearing run-in (shakedown) is shown as reduction in the conductivity increase. More than about 30 minutes prior to the final forced shutdown of the trial run by an oscillation sensor, the conductivity remains almost constant followed by a temporary rise directly before disconnection. After switching off the test gear, the oil conductivity decreases strongly. This clearly emphasizes the influence of the additives. During the loading stages, more impurities per time unit are produced than bound to additives. After shutting down the test rig, no further oil contamination occurs while the effect of additives still continues.

The variations in electrical conductivity are depicted in Figure 12. In this diagram, the curve follows averages respectively calculated over 3 minutes.

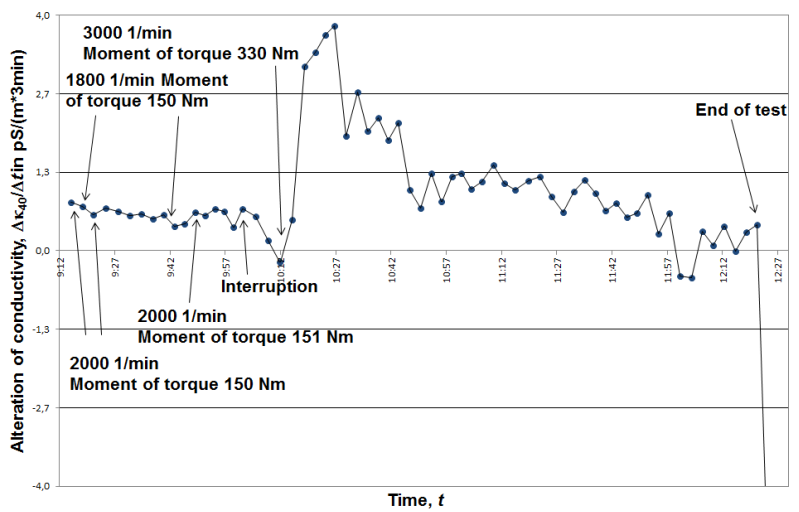

Figure 12. Alteration of the electrical conductivity, expressed as $\Delta \mathrm{k}_{40} / \Delta t$, vs. running time $t$. 
When starting up at 2000 revolutions per minute and a torque of $150 \mathrm{Nm}$, a relatively constant change in conductivity from 0.6 to $0.8 \mathrm{pS} /(\mathrm{m} \times 3 \mathrm{~min})$, equivalent to 3.3 to $4.4 \mathrm{fS} /(\mathrm{m} \times \mathrm{s})$, occurs. In the case of higher load $\left(330 \mathrm{Nm}, 3000 \mathrm{~min}^{-1}\right)$, the change in conductivity rises up to $3.8 \mathrm{pS} /$ $(\mathrm{m} \times 3 \mathrm{~min})$, i.e. $21.1 \mathrm{fS} /(\mathrm{m} \times \mathrm{s})$. After the intermediate load increase, the effect on the change of the oil conductivity appears stronger. This may be attributed to the time-dependent formation of impurities and changes in bearing stressing as can be expected during the development of spalling. Figure 13 shows the inner ring of the failed planet bearing with massive damage of the raceway at the end of the trial.

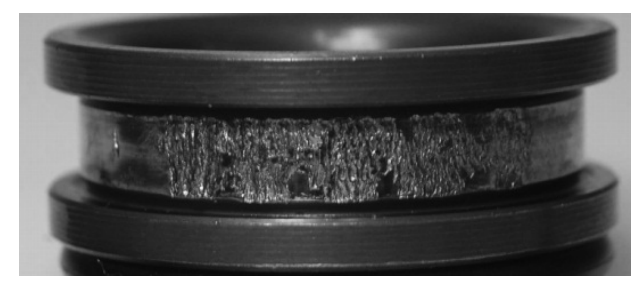

Figure 13. Heavily spalled inner ring raceway of the tested cylindrical roller bearing.

The connection between the change in conductivity $\kappa$ and the loss of power $\Delta P$ in the gear is also evaluated. Figure 14 represents this progress graphically. Both the increasing change in oil conductivity and the gear power loss correlate with the bearing wear.

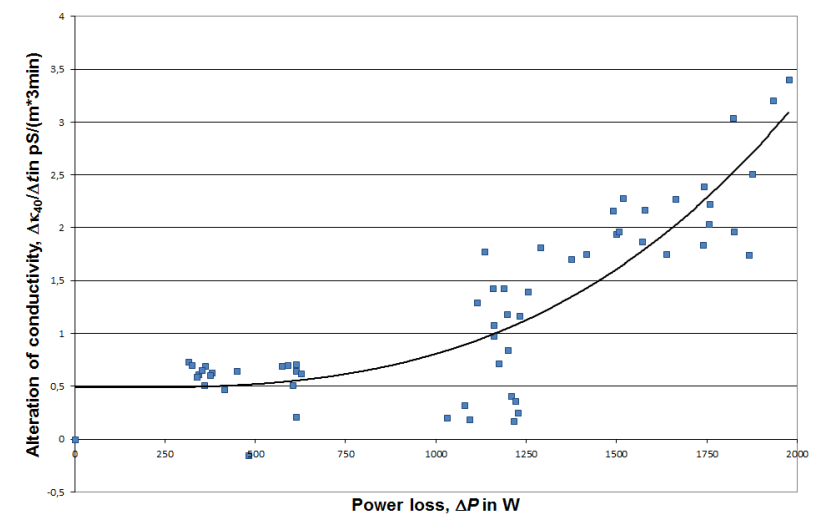

Figure 14. Alteration of the electrical conductivity as function of power loss of the gearbox.

In the diagram of Figure 14, a trend line is drawn as polynomial of the third order. The higher the increases in conductivity and loss of power in the gear, the stronger the bearing wear occurs. Exceptional changes to the system, e.g. switching of the load conditions, are not taken into account. 


\subsection{Relative permittivity of the lubricating oil}

In addition to the electrical conductivity, the relative permittivity $\varepsilon_{\mathrm{r}}$ of the oil is measured. In the case of oils not enriched with additives, the water content can be determined that way. There are good prospects that the dwindling efficacy of the additives can be detected by means of the dielectric constant measurement. Figure 15 shows the time development of the relative permittivity during the trial run. Due to the dependence on temperature, this development is also depicted in the diagram.

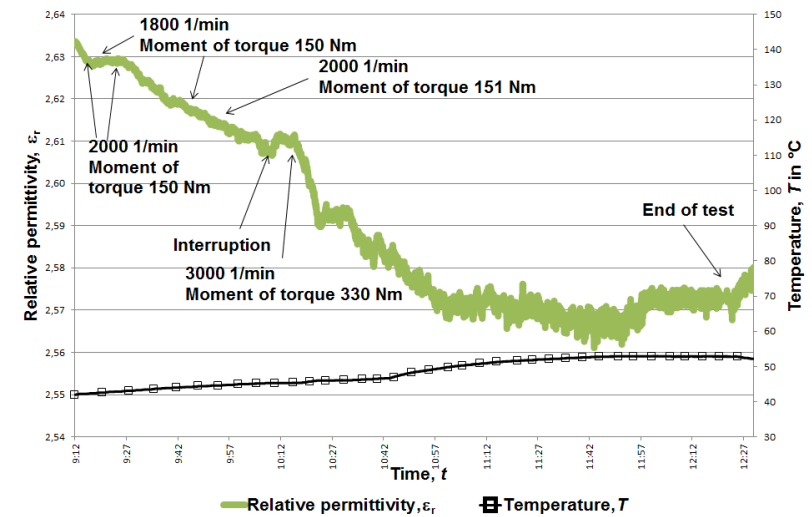

Figure 15. Time curves of the relative permittivity $\varepsilon_{\mathrm{r}}$ and the temperature $T$ as a function of the running time $t$.

The change of the relative permittivity could be caused by a combination of the effects of a chemical reaction of additives, water evaporation from the oil and the temperature dependence of the cell constants as well as the relative permittivity itself. During the trial run, the temperature increases from 42 to $52.9^{\circ} \mathrm{C}$. The temperature dependence justifies the developed adaptive, self-learning temperature compensation technique. Figure 16 shows the temperature compensated time development of the relative permittivity during the gear trial.

\section{Approach for condition monitoring of additivated lubricating oils}

A direct connection between the electrical conductivity and the degree of contamination of oils is found. An increase of the electrical conductivity of the oil in operation can thus be interpreted as increasing wear or contamination of the lubricant. The aging of the oil is also evident in the degradation of additives. The used additives reveal high conductivity compared with the oil.

The consumption of the additives is reflected in a reduction of the electrical conductivity and permittivity of the oil. The gradient, i.e. the time derivative, of the conductivity or the dielectric constant progression respectively represents a measure of the additive degradation and consumption. The full additive degradation is indicated by the slope of zero (bathtub curve). 


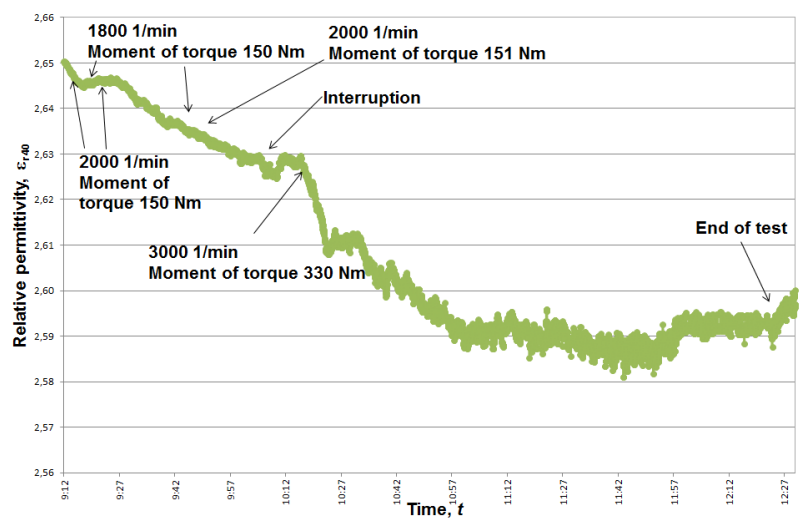

Figure 16. Time curve of the temperature compensated relative permittivity $\varepsilon_{\mathrm{r}}$.

Then the measurement signal increases further with increasing pollution, water entry, etc. Figure 17 schematically shows the temperature compensated time curve of the permittivity of additivated oil continuously contaminated by the addition of wear debris, water or oil acids from chemical aging. Once the additives are consumed, the vanishing shielding effect results in a characteristic re-increase.

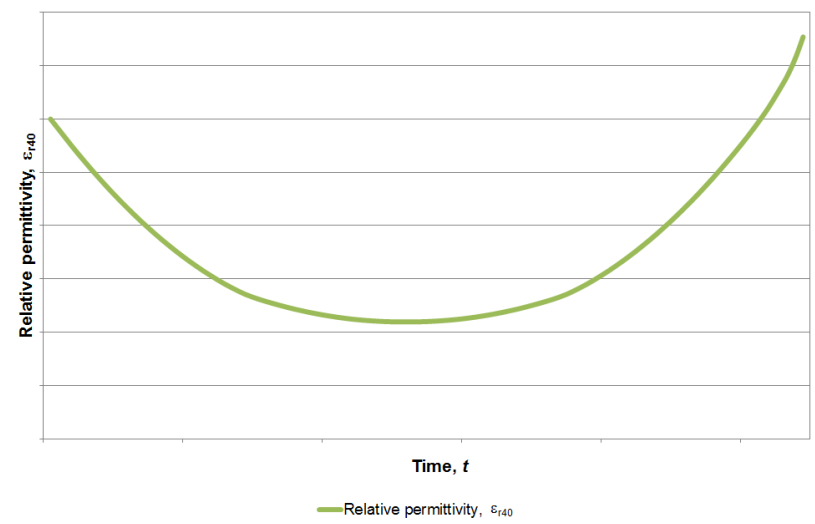

Figure 17. Temperature compensated permittivity.

The most commercially available particle counters only detect particles as small as $4 \mu \mathrm{m}$. In a very early stage of wear of bearings, gears, hydraulic cylinders, etc., however, particularly smaller particles are produced. A preventive maintenance lowing, rather than rigid inspection intervals, therefore requires recognition of even the smallest particles. These particles are far more common in the oils of functioning machines than larger ones. Oil aging can be involved in the failure, for instance, of rolling bearings [7]. 


\section{Web-based decentralized lubricant quality monitoring system}

The integration into a suitable communication structure and the realization of an online monitoring system offers an interesting practice-oriented utilization of the oil sensor system. This is briefly discussed below.

Preferred areas of application of the sensor system are energy production and automated technical plants that are operated locally, like e.g. wind turbines, generators, hydraulic systems or gearboxes. Plant employers are interested in continuous automated in vivo examination of the oil quality rather than interrupting the operation for regular sampling. Online oil status monitoring significantly improves the economic and ecological efficiency by increasing operating safety, reducing down times or adjusting oil change intervals to actual requirements. Once the oil condition monitoring sensors are installed on the plants, the measuring data can be displayed and evaluated elsewhere. A flexible decentralized monitoring system also enables the analysis of measuring signals and monitoring of the plants by external providers. A userorientated service ensuring the quantitative evaluation of changes in the oil-machine system, including the recommendation of resulting preventive maintenance measures, relieves plant operators, increases reliability and saves costs.

In a web-based decentralized online oil condition monitoring system, the sensor signals are preferably transferred through the Internet to a database server and recorded on an HTML page as user interface [8]. Figure 18 shows the displayed measured data.

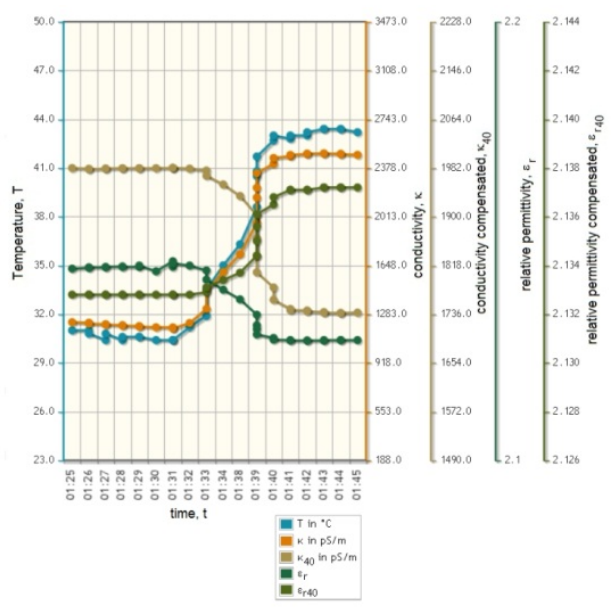

Figure 18. Displayed measured data.

Following authentication, a simple web browser permits access via the wired or wireless LAN. In case of alarm signals, an immediate automated generation of warning messages, for instance by e-mail or SMS, is possible from any computer with Internet connection. Figure 19 shows the new sensor system with communication unit [9]. 


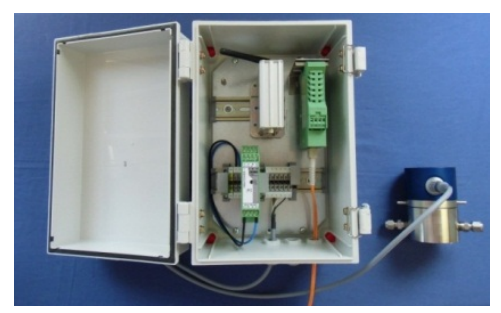

Figure 19. WearSens" sensor system with communication unit.

\section{Conclusions}

The online diagnostics system measures components of the specific complex impedance of oils. For instance, metal abrasion due to bearing wear at the tribological contact, broken oil molecules, acids or oil soap cause an increase in electrical conductivity that directly correlates with the degree of pollution of the oil. The dielectrical properties of the oils are especially determined by the water content, which, in the case of products that are not enriched with additives, becomes accessible by an additional accurate measurement of the relative permittivity. In the case of oils enriched with additives, statements on the degradation of additives can also be deduced from recorded changes in the relative permittivity.

Indication of damage and wear is measured as an integral factor of, e.g., the degree of pollution, oil aging and acidification, water content and the decomposition state of additives or abrasion of the bearings. It provides informative data on lubricant aging and material loading as well as the wear of the bearings and gears for the online operative monitoring of components of machines. Additional loading, for instance, by vibration induced mixed friction in rollingsliding contact (rolling bearings, gears, cams, etc.) causes specific faster oil aging, e.g., in the course of premature component failures. Verified in roller bearing vibration rig tests, the oil suffers from significant acidification by polycondensation reactions and incipient resinification, as proven by infrared spectroscopy of used lubricant. The application potential of the sensor is discussed on the example of the prevention of early rolling bearing failures in industrial gearboxes, of which vibrational contact loading is the root cause.

For an efficient machine utilization and targeted damage prevention, the new electrical online oil condition monitoring system offers the prospect to carry out timely preventative maintenance on demand rather than in rigid inspection intervals. The determination of impurities or reduction in the quality of the lubricants and the quasi continuous evaluation of the bearing and gear wear and oil aging meet the holistic approach of a real-time monitoring of a change in the condition of the oil-machine system.

The measuring signals can be transmitted to a web-based condition monitoring system via LAN, WLAN or serial interfaces of the sensor system. The monitoring of the tribological wear mechanisms during proper operation below the tolerance limits of the components then allows 
preventive, condition-oriented maintenance to be carried out, if necessary, long before regular overhauling, thus reducing outages caused by wear while simultaneously increasing the overall lifetime of the oil-machine system.

On a bearing and gear rig test, various load cycles are run and the functionality of the introduced electric online condition monitoring sensor system is tested successfully. The evaluation of the experiment is presented.

\section{Author details}

Manfred R. Mauntz ${ }^{1 *}$, Jürgen Gegner², Ulrich Kuipers ${ }^{3}$ and Stefan Klingau ${ }^{1}$

*Address all correspondence to: mrm@cmc-instruments.de

1 cmc Instruments GmbH, Eschborn, Germany

2 University of Siegen, Siegen, Germany

3 South Westphalia University of Applied Sciences, Hagen, Germany

\section{References}

[1] Gegner, J., Kuipers, U., Mauntz, M. Ölsensorsystem zur Echtzeit-Zustandsüberwachung von technischen Anlagen und Maschinen, Technisches Messen 77; 2010. pp. 283-292.

[2] Kuipers, U., Mauntz, M. Ölsensorsystem - Sensorsystem zur Messung von Komponenten der komplexen Impedanz elektrisch gering leitender und nichtleitender Fluide, dessen Realisierung und Anwendung, German Patent Application N 102008 047 366.9, Applicant: cmc Instruments GmbH, German Patent Office, Munich, Filing date: 15.09 .2008 , in German.

[3] Kuipers, U., Mauntz, M. Verfahren, Schaltungsanordnung, Sensor zur Messung physikalischer Größen in Fluiden sowie deren Verwendung, European Patent Application N EP 09000244, European Patent Office, Munich; 09.01.2009, in German.

[4] Lichtenecker, K., Rother, K. Die Herleitung der logarithmischen Mischungsgesetzes aus allgemeinen Prinzipien der stationären Strömung, Physikalische Zeitschrift, 1931, 32, pp. 255-260.

[5] Gegner, J. Tribological Aspects of Rolling Bearing Failures, In: C.-H. Kuo (ed.), Tribology - Lubricants and Lubrication, Rijeka: InTech; 2011. Chap. 2, pp. 33-94. 
[6] Nierlich, W., Gegner, J. Einführung der Normalspannungshypothese für Mischreibung im Wälz-Gleitkontakt, Düsseldorf: VDI Reports 2147, VDI Wissensforum; 2011. pp. 277-290, in German.

[7] Gegner, J., Nierlich, W. Operational Residual Stress Formation in Vibration-Loaded Rolling Contact, Advances in X-ray Analysis, Vol. 52; 2008, pp. 722-731.

[8] Nierlich, W., Gegner, J. Material Response Bearing Testing under Vibration Loading, In: J. M. Beswick (ed.), Advances in Rolling Contact Fatigue Strength Testing and Related Substitute Technologies, STP 1548, ASTM International, West Conshohocken, Pennsylvania, USA, 2012.

[9] Gegner, J., Kuipers U., Mauntz, M. New Electric Online Oil Condition Monitoring Sensor - an Innovation in Early Failure Detection of Industrial Gears, 4th International Multi-Conference on Engineering and Technological Innovation, 19.-22-07.2011, Orlando, Florida, USA 2011, Proceedings Volume I, International Institute of Informatics and Systemics, Winter Garten, Florida, USA, 2011, pp. 238-242.

[10] Gegner, J., Kuipers U., Mauntz, M. High-precision online sensor condition monitoring of industrial oils in service for the early detection of contamination and chemical aging, Sensor+Test Conferences 07.-09.06.2011, Nürnberg, AMA Service GmbH, Wunstorf, 2011, pp. 702-709. 
